\title{
Apoptosis of resident and inflammatory macrophages before and during the inflammatory response of the virgin bovine mammary gland
}

Zbysek Sladek ${ }^{1,2^{*}}$, Dusan Rysanek ${ }^{2}$

\begin{abstract}
Background: Macrophages may play a prominent role in defense of the bovine mammary gland, and their functionality is necessary for successful eradication of bacterial pathogens. In contrast to necrosis, however, apoptosis has not yet been studied in macrophages from bovine mammary glands. Therefore, the aim of this study was to confirm the occurrence of apoptosis in macrophages from resting heifer mammary glands and during the inflammatory response.
\end{abstract}

Methods: Inflammatory response was induced by phosphate buffered saline (PBS) and by lipopolysaccharide (LPS). Resident macrophages (RESMAC) were obtained before and inflammatory macrophages (INFMAC) 24, 48, 72 and 168 hours after inducing inflammatory response in mammary glands of unbred heifers. Cell samples were analyzed for differential counts, apoptosis and necrosis using flow cytometry.

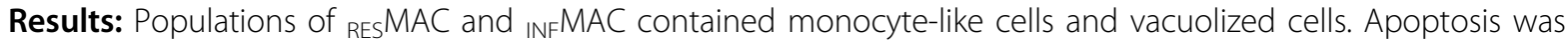
detected differentially in both morphologically different types of ${ }_{R E S} M A C$ and ${ }_{I N F} M A C$ and also during initiation and

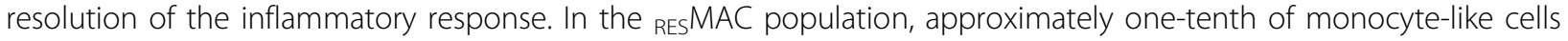

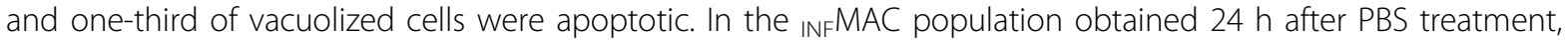
approximately one-tenth of monocyte-like cells and almost one-quarter of vacuolized cells were apoptotic. At the same time following LPS, however, we observed a significantly lower percentage of apoptotic cells in the

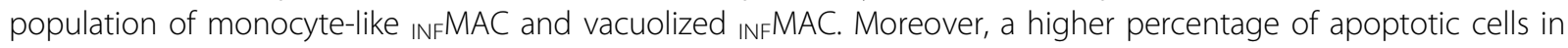
INFMAC was detected during all time points after PBS in contrast to LPS. Comparing RESMAC and INFMAC, we

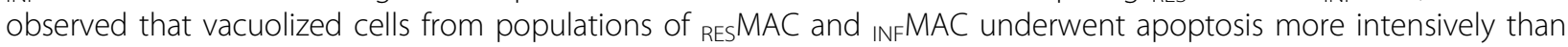
did monocyte-like cells.

Conclusions: We conclude that apoptosis of virgin mammary gland macrophages is involved in regulating their lifespan, and it is involved in the resolution process of the inflammatory response.

\section{Background}

Heifers' mammary glands are susceptible to bacterial infections just as are the lactating and non-lactating mammary glands of cows. Intramammary quarter infection occurrence is very high and may reach nearly $75 \%$ in the prepartum period of heifers [1]. The prevalence of intramammary infections in heifers around calving

\footnotetext{
* Correspondence: zbysek.sladek@mendelu.cz

'Department of Morphology, Physiology and Animal Genetics, Mendel University, Zemedelska 1, 61300 Brno, Czech Republic
}

time is very high as well. Unfortunately, little information is available about these infections' relevance for the heifers and relation to post-partum clinical mastitis [2].

A cellular defense system is present in the heifer mammary gland to resist invading bacteria, and it includes macrophages, lymphocytes, and polymorphonuclear leukocytes (PMN) [3-5]. This resident cell population is an early sensor of infection and initiates the immune response following pathogen entry through the teat canal. It is especially important in virgin mammary
C Biomed Central

(c) 2010 Sladek and Rysanek; licensee BioMed Central Ltd. This is an Open Access article distributed under the terms of the Creative Commons Attribution License (http://creativecommons.org/licenses/by/2.0), which permits unrestricted use, distribution, and reproduction in any medium, provided the original work is properly cited. 
gland, because there is no cell renewal due to regular milking as in the lactating mammary gland of cows.

Once invading pathogens are detected, the resident macrophages release cytokines, eicosanoids, acute phase proteins and chemoattractants that direct migration of PMN from the blood into the infected area [6,7]. The influx of PMN is followed by the infiltration from the bloodstream of monocytes, which mature locally into inflammatory macrophages [3] and phagocytose bacteria together with PMN [8]. Once the initiating noxious materials are removed via phagocytosis, the inflammatory reaction must still be resolved. Therefore, PMN undergo apoptosis (programmed cell death) and are subsequently phagocytosed by macrophages in bovine mammary glands [9-11].

It is evident that macrophages play a critical role in the initiation, maintenance, and resolution of inflammation [12]. Nevertheless, the high incidence of intramammary infection suggests that the heifer mammary gland's defense system fails to prevent bacterial infections [13]. Macrophages, as a dominant cell type, may be responsible for this situation. Even though these were discovered many years ago $[3,14]$, very little is known about the basic biological features of macrophages in heifer mammary glands.

It is generally known that macrophages are long-lived cells that may persist in the non-inflamed tissues for weeks [15]. Throughout this period, and until they reemigrate into supramammary lymphatic nodes [16], macrophages need to retain viability if they are to function fully. Not all macrophages can re-emigrate, however, and part of them die by necrosis inside of the mammary gland [17].

It has been observed that in addition to necrosis macrophages also undergo apoptosis locally. Apoptosis has been observed in alveolar, peritoneal and pleural macrophages in response to pathogenic and non-pathogenic stimuli, and a number of mechanisms are recognized as driving this process [18].

It is surprising that little is yet known about macrophage apoptosis in bovine veterinary medicine [19-22] in comparison to human medicine. Furthermore, in contrast to PMN [9-11] and to lymphocytes [23], apoptosis has not yet been studied in macrophages from bovine mammary glands. Therefore, it remains unclear whether apoptosis is involved in regulating the lifespan in macrophages and whether apoptosis of these cells participates in the inflammatory response of the virgin mammary gland.

The aim of this study, therefore, was to confirm the occurrence of apoptosis in macrophages from resting heifer mammary glands and during an inflammatory response. For this purpose, an inflammation model based on induction of inflammatory response in mammary glands of virgin heifers was used. We analyzed two different populations of macrophages - resident macrophages obtained from intact mammary glands, and inflammatory macrophages - through an experimental inflammatory response induced by bacterial and nonbacterial agents.

\section{Methods}

\section{Animals}

The experiments were carried out on 40 mammary glands of 10 virgin, clinically healthy Holstein $\times$ Bohemian Pied crossbred heifers aged 15 to 20 months. The heifers were housed in an experimental tie-stall barn and fed a standard ration consisting of hay and concentrates with mineral supplements. The experimental tiestall used in this study is certified. The animal care conformed to good care practice protocol. All experimental procedures were approved by the Central Commission for Animal Welfare of the Czech Republic. All heifers were free of intramammary infections, as demonstrated by bacteriological examination of mammary lavages.

\section{Experimental design}

Two populations of macrophages were studied: the population of resident macrophages and the population of inflammatory macrophages obtained before and after inflammatory induction of mammary glands respectively, using phosphate buffered saline (PBS) and lipopolysaccharide (LPS). After inflammatory induction, macrophages were collected at four time points $(24,48,72$ and 168 hours). In the fresh cell populations obtained, the total cell count was assessed by the fluoro-opto-electronic method. The differential leukocyte count and number of apoptotic and necrotic cells were detected by flow cytometry (FCM). Moreover, the cells were cultivated in vitro and thereafter apoptosis, necrosis, CD11b and CD14 expressions were analyzed by FCM. Finally, cytolysis was assessed by ELISA 1 actate dehydrogenase (LDH) determination.

\section{Isolation of resident and inflammatory macrophages}

The untreated mammary glands of virgin heifers were rinsed with PBS to obtain the cell population. The population was composed of the resident cells from the mammary glands, which had never before been rinsed. This population of macrophages was designated as resident macrophages (RESMAC). The procedure has been used and described many times in our previous studies $[24,25]$. Briefly, modified urethral catheters (AC5306CH06, Porges S.A., France) were inserted into the teat canal after a thorough disinfection of the teat orifice with $70 \%$ ethanol. Through the catheter, each mammary quarter was injected with $20 \mathrm{~mL}$ of PBS $(0.01$ M, pH 7.4; NaCL 0.138 M; KCL 0.0027 M, prepared with apyrogenic water) and lavages were immediately collected back through the catheter directly to the 
syringe. Immediately after harvesting resident cells, the mammary glands were treated with PBS $(\mathrm{n}=20)$ or LPS ( $\mathrm{n}=20 ; 10 \mu \mathrm{g}$ of LPS from Escherichia coli serotype O128:B12, Sigma, St. Louis, MO, USA) to induce an inflammatory response [25]. Inflammatory cell samples were obtained through lavage 24-168 h after administration of the PBS or LPS. These samples were identified as inflammatory macrophages (INFMAC).

\section{Cell processing and in vitro cultivation}

Bacteriological examinations of all lavages were performed by culture on blood agar plates $(5 \%$ washed ram erythrocytes) with aerobic incubation at $37^{\circ} \mathrm{C}$ for $24 \mathrm{~h}$ in duplicates. Only animals with sterile cultivation findings were included into the experiment. Total mammary cell counts in lavages were determined using the Fossomatic 90 apparatus (Foss Electric, Denmark) and the procedure recommended by the International Dairy Federation [26]. Cell suspensions were centrifuged at $4{ }^{\circ} \mathrm{C}$ and $200 \times \mathrm{g}$ for $10 \mathrm{~min}$. One milliliter of supernatant was retained for resuspension of the pellet. The remaining supernatant was decanted. All populations of macrophages were adjusted $\left(5 \times 10^{6}\right.$ cells $\left./ \mathrm{mL}\right)$ in an RPMI 1640 medium (Sigma, MO, USA). A part of these cells was immediately analyzed (as a fresh cell population), and the remainder was incubated in vitro. Macrophages were put into microplates $(6 \times 4$ Costar Ultraplates, CA, USA) and were incubated for 0,3 and $6 \mathrm{~h}$ at $37^{\circ} \mathrm{C}$. Following the incubation periods, incubated cells were analyzed using FCM. LDH was determined in the incubation medium.

\section{Flow cytometry}

Each sample designated for FCM analysis was divided into two parts for detecting viability (apoptosis and necrosis) and for detecting CD14 and CD11b expression. The differential cell count was processed according to Sladek et al. [25] based on light scatter properties (Fig. 1). Apoptotic and necrotic macrophages were analyzed by FCM after being simultaneously stained with Annexin-V labeled with FITC and PI as described by Vermes et al. [27]. The commercial Annexin-V-FLUOS Staining Kit (Boehringer Mannheim, Mannheim, Germany) was used according to the manufacturer's instructions. For detecting CD14 by FCM, mouse antiovine CD14 (VPM65, Serotec, Oxford, UK) diluted 1:20 and PE-labeled swine anti-mouse IgG1 (SouthernBiotech, Birmingham, AL, USA), diluted 1:360, were used as the primary and secondary antibodies, respectively [25]. For detecting CD11b, MM10A (VMRD Inc., Pullman, WA, USA) diluted 1:20 and FITC labeled IgG2b (SouthernBiotech, Birmingham, Alabama, USA) diluted 1:100 were used as the primary and secondary antibodies, respectively. Negative control samples for AnnexinV and PI were not stained. Negative control samples for CD14 and CD11b were stained with the secondary antibody only. For analysis, we used the FACS Calibur flow cytometer with CELLQuest ${ }^{\mathrm{TM}}$ software (Becton Dickinson, Mountain View, CA, USA). The instrument setting for FCM was set to analyze 20,000 cells per sample.

\section{In vitro detection of cytolysis}

The Cytotoxicity Detection Kit (Roche Diagnostic $\mathrm{GmbH}$, Panzberg, Germany) was used to quantify mammary leukocyte cytolysis under the procedure used previously [28].

\section{Statistical analysis}

Total cell count values were transformed by logarithmic transformation. All experimental characteristics - the cell counts (in logarithmic transformation), concentrations and the proportions - were tested for normal data distribution using the Shapiro-Wilk test. To determine significant sources of variability, the results were analyzed by multifactorial analysis of variance. The signifi-

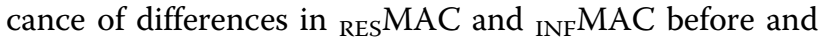
during the inflammatory response and during in vitro cultivation were tested by determining the proportions of apoptotic and necrotic cells, CD $14^{+}$and $C D 11 b^{+}$ cells, and LDH concentrations. These parameters were tested using Scheffé's method. Statistical analyses were carried out using STAT Plus software [29].

\section{Results}

Resident and inflammatory macrophages before and during inflammatory response

The untreated mammary glands contained a resident cell population with relatively low total cell counts $(0.6 \pm 0.3 \times$ $\left.10^{6} / \mathrm{mL}\right)$. These cells were mainly comprised of ${ }_{\mathrm{RES}} \mathrm{MAC}$ $(53.8 \pm 11.2 \%)$ and lymphocytes $(36.1 \pm 12.6 \%)$, and much less of PMN (10.1 $\pm 7.2 \%)$ (Fig. 2). In the ${ }_{\mathrm{RES}} \mathrm{MAC}$ population, monocyte-like cells and a large number of vacuolized cells were observed (for a detailed structure and ultrastructure see Sladek and Rysanek [17]). Expression of integrin receptor $\mathrm{CD} 11 \mathrm{~b}$ on the surfaces of these cells was very low, at $27.9 \pm 5.5 \%$ in monocyte-like RESMAC and $18.7 \pm 2.1 \%$ in vacuolized ${ }_{\mathrm{RES}} \mathrm{MAC}$.

Intramammary application of PBS or LPS induced the inflammatory response, which was characterized by an influx of inflammatory cells. The total inflammatory cells count culminated at $24 \mathrm{~h}$ after treatment, and it was significantly higher following LPS than after PBS during all time points after treatment $(P<0.01$, except $P<0.05168$ h) (Tab. 1).

In the initial stage of the inflammatory response (24 h), PMN comprised the dominant cell type in proportions of more than $50 \%$ and $90 \%$, respectively, after PBS and LPS treatments (Fig. 2). In this time we determined only fleeting clinical signs (mild pain and moderate swelling) in examined animals, and particularly after LPS intramammary administration. 

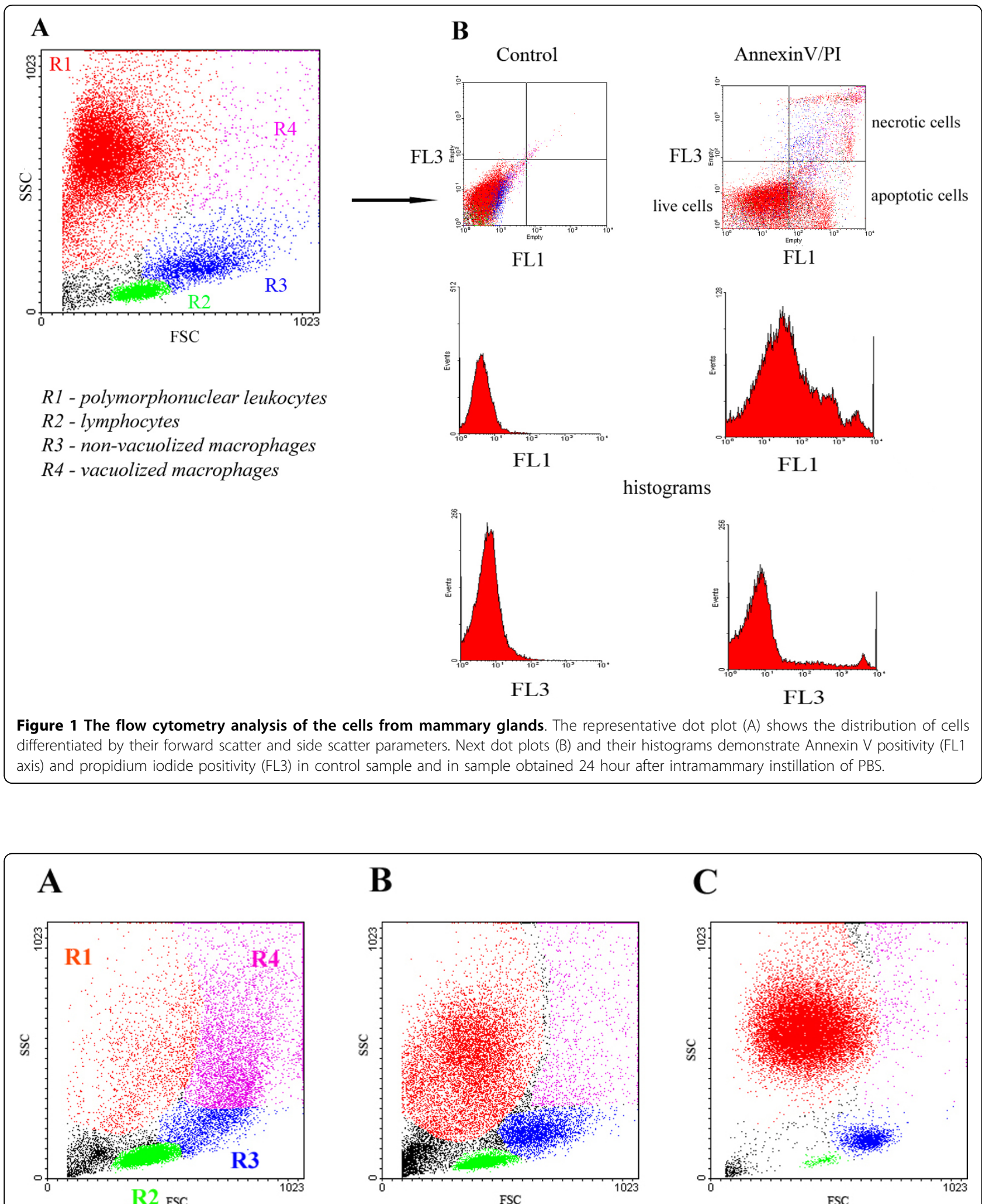

\section{B}

\section{C}
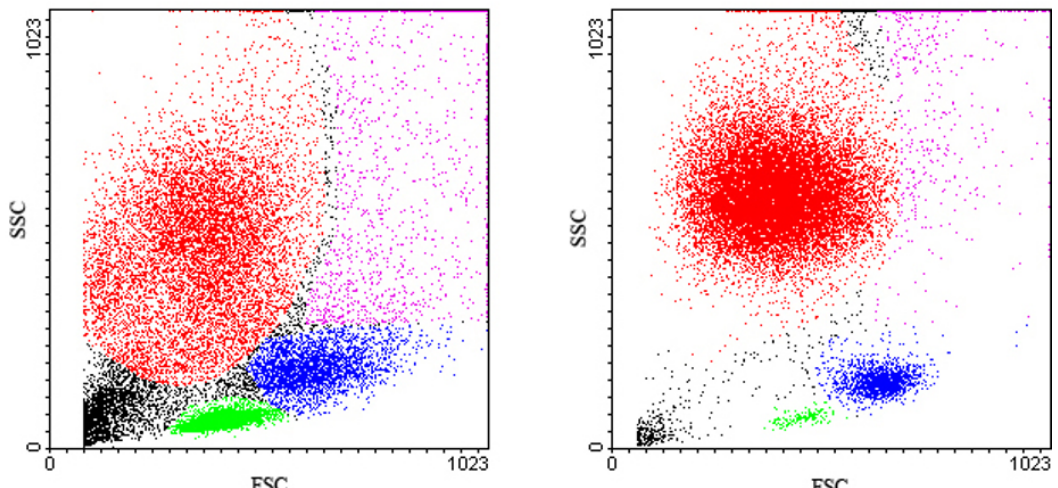

FSC

Figure 2 The flow cytometry analysis of resident and inflammatory leukocytes from mammary glands. Region distribution in dot plots of leukocytes from untreated heifer mammary glands (A) and leukocytes obtained 24 hour after intramammary instillation of PBS (B) and LPS (C) : polymorphonuclear leukocytes region (R1), lymphocyte region (R2), monocyte-like macrophages region (R3), and vacuolised macrophage region (R4). 
On the other hand, the resolution stage of the inflammatory response was characterized by the decrease in the PMN proportion (48 - $168 \mathrm{~h}$ ). The proportion of macrophages increased at the same time, and $168 \mathrm{~h}$ after treatment it was very similar to that of the untreated mammary gland (data not shown).

Similarly to RESMAC from untreated mammary glands, INFMAC were also represented by two morphologically distinct types: monocyte-like cells and vacuolized cells with phagocytosed apoptotic PMN. The proportions of both types of macrophages in populations of ${ }_{\mathrm{RES}} \mathrm{MAC}$ and INFMAC before and during the inflammatory response are shown in Fig. 3a, b.

In contrast to RESMAC, the expression of integrin receptor $\mathrm{CD} 11 \mathrm{~b}$ was significantly greater $(P<0.01)$ on the surface of monocyte-like and vacuolized INFMAC after PBS $(64.4 \pm 12.4 \%$ and $93.7 \pm 1.7 \%)$ and after LPS $(75.1 \pm 13.1 \%$ and $99.5 \pm 0.5 \%)$.

\section{Apoptosis and necrosis of resident macrophages from} untreated heifer mammary glands

Apoptotic and necrotic cells were differentially detected in both morphologically different types of ${ }_{\text {RES MAC. In }}$ the RESMAC population approximately one-tenth of monocyte-like cells and one-third of vacuolized cells were apoptotic (Fig. 4a, b). Necrosis was observed in $7 \%$ of monocyte-like RES MAC and in $23 \%$ of vacuolized RESMAC.

\section{Apoptosis and necrosis of inflammatory macrophages} during the inflammatory response

In the INFMAC population obtained $24 \mathrm{~h}$ after PBS treatment, approximately one-tenth of monocyte-like cells and almost one-quarter of vacuolized cells were apoptotic (Fig. 4a, b). At the same time after LPS treatment, however, we observed a insignificantly lower proportion of apoptotic cells in the population of monocyte-like ${ }_{\text {INF }} \mathrm{MAC}$ and vacuolized ${ }_{\text {INF }}$ MAC (Fig. 4a, b).

Moreover, a higher proportion of apoptotic cells in populations of monocyte-like INFMAC and vacuolized INFMAC was detected during all time points after PBS in contrast to LPS. As is evident from Fig. 4a, statistically significant differences between proportions of apoptotic cells were observed for $48-168 \mathrm{~h}(P<0.01)$ in monocyte-like INFMAC while no significant differences existed for vacuolized INFMAC. Furthermore, when comparing RESMAC and INFMAC, we observed that

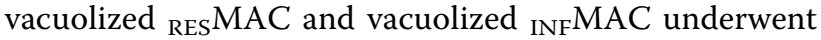
apoptosis more intensively than did monocyte-like RESMAC and monocyte-like INFMAC.

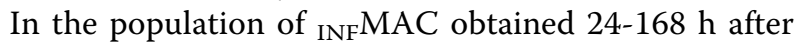
PBS treatment, fewer than $5 \%$ of monocyte-like cells and fewer than $20 \%$ of vacuolized cells were necrotic. In addition, we observed an insignificantly higher proportion of necrotic cells in the population of monocyte-like
INFMAC 24-168 $\mathrm{h}$ after LPS treatment. In the population of vacuolized INFMAC, we also detected a higher proportion of necrotic cells after LPS than PBS treatment (except at the time point $168 \mathrm{~h}$ ). Differences between the proportions of necrotic cells were at no time significant during the experimental period.

Apoptosis and necrosis of resident and inflammatory macrophages in vitro

In vitro cultivation of ${ }_{\mathrm{RES}} \mathrm{MAC}$ and ${ }_{\mathrm{INF}} \mathrm{MAC}$ led to great changes in the proportions of apoptotic and necrotic cells.

We observed after in vitro cultivation of ${ }_{\mathrm{RES}} \mathrm{MAC}$ that the proportion of apoptotic cells was significantly increased only in monocyte-like cells $(P<0.05)$ (Fig. $5 a)$. After in vitro cultivation of ${ }_{\text {INF }} \mathrm{MAC}$, on the other hand, apoptosis was significantly increased in monocytelike cells only after PBS $(P<0.05)$ and in vacuolized cells after PBS $(P<0.05)$ and LPS $(P<0.05)$ (Fig. 5a, b). The morphological features of apoptosis in monocyte-

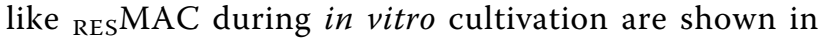
Fig. 6.

Similarly to apoptosis, the proportions of necrotic cells were significantly increased in all populations of RESMAC (except monocyte-like cells) and INFMAC during in vitro cultivation (data not shown).

\section{Effect of incubation time on cell loss}

In vitro cultivation was also accompanied by an increase of LDH in all populations of macrophages (Fig. 7), indicating cell loss. The highest level of cytolysis was

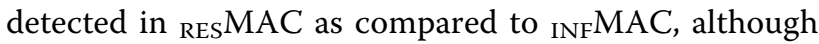
the cytolysis of ${ }_{\text {INF }}$ MAC following treatment with PBS was higher than after LPS. These results indicate a significantly higher cell loss in the RESMAC population in comparison with that of ${ }_{\text {INF }} \mathrm{MAC}$ during in vitro cultivation.

\section{CD14 expression in resident and inflammatory}

\section{macrophages in vitro}

In vitro cultivation was accompanied by a differential activation of RESMAC and INFMAC, which was evident from the change in the proportion of CD14 ${ }^{+}$cells. As demonstrated in Fig. 8a, b, the proportion of CD14 $4^{+}$ cells was increased in all populations of macrophages during in vitro cultivation. However, significant differences were observed only in the populations of monocyte-like ${ }_{\text {INF MAC }}(P<0.01)$ and vacuolized ${ }_{\text {INF MAC }}(P$ $<0.05)$ obtained $24 \mathrm{~h}$ after LPS treatment.

\section{Discussion}

The aim of this study was to confirm the occurrence of apoptosis in resident and inflammatory macrophages from heifer mammary glands, as no data is available on this subject in veterinary medicine. In this pilot study, an inflammation model based on inducing inflammatory response in mammary glands of virgin heifers was used. 
(a)

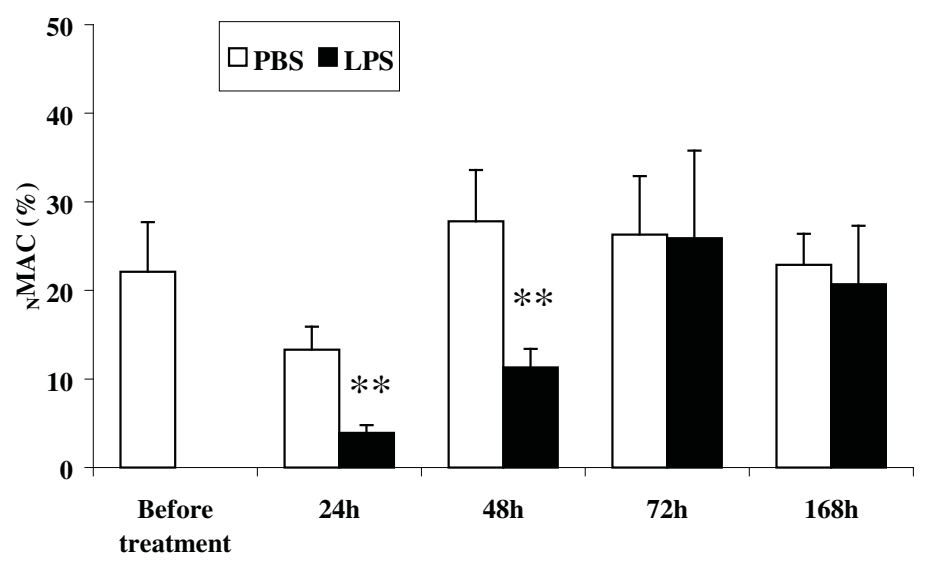

(b)

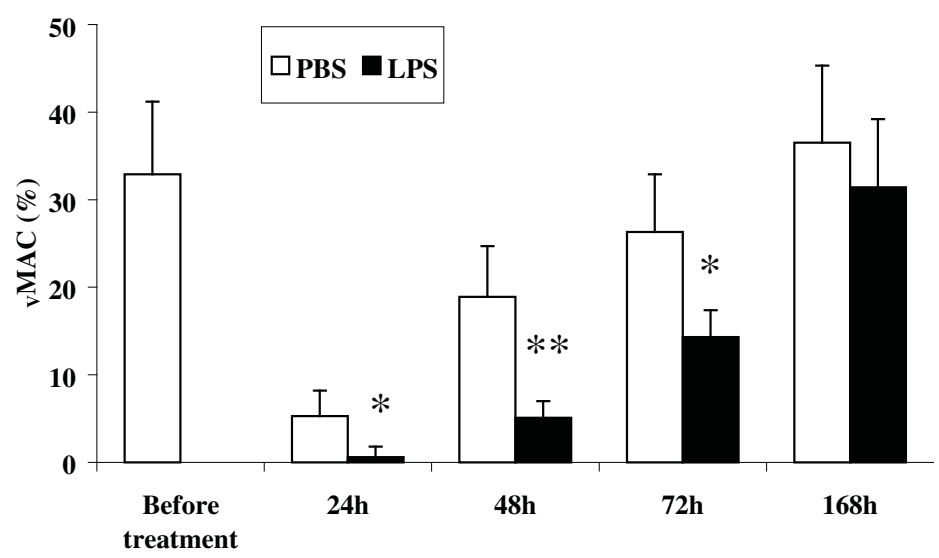

Figure 3 Differential proportion of macrophages. Differential proportion of non-vacuolized (a) and vacuolized macrophages (b) (mean \pm S.D.) in mammary lavages collected before and at 24, 48, 72, and $168 \mathrm{~h}$ after intramammary instillation of PBS or LPS. Significant between-treatment differences are marked with asterisks $\left({ }^{*} P<0.05 ;{ }^{* *} P<0.01\right)$.

The mammary gland of heifers is characterized by the presence of three distinct populations of resident cells: macrophages, lymphocytes and PMN. Previously, it had been observed that PMN and lymphocytes may undergo apoptosis. Moreover, it had been established that apoptosis of these cells plays an important role during the inflammatory response of mammary glands $[9,11,23,30]$. In this study, we determined that macrophages of heifer mammary glands also undergo apoptosis. To our knowledge, this is the first study that dealing with apoptosis of macrophages from bovine mammary glands.

RESMAC from heifer mammary glands comprise the dominant cell population, which consists of two morphologically different cell types. They are sometimes categorized as monocytes (non-vacuolized, monocytelike cells) and numerous (vacuolized) macrophages $[3,22,25,31]$. This morphological categorization of macrophages from bovine mammary glands is important. As the two types of macrophages have different biological features [25,31], we expected different proportions of apoptosis and necrosis in the two populations of macrophages.

In this study, we observed approximately $10 \%$ apoptotic and less than $8 \%$ necrotic cells in the fresh population of monocyte-like RESMAC. This low proportion of death cells is to be expected, because monocyte-like RESMAC are relatively young cells in comparison to vacuolized RESMAC. It has been suggested that 
(a)

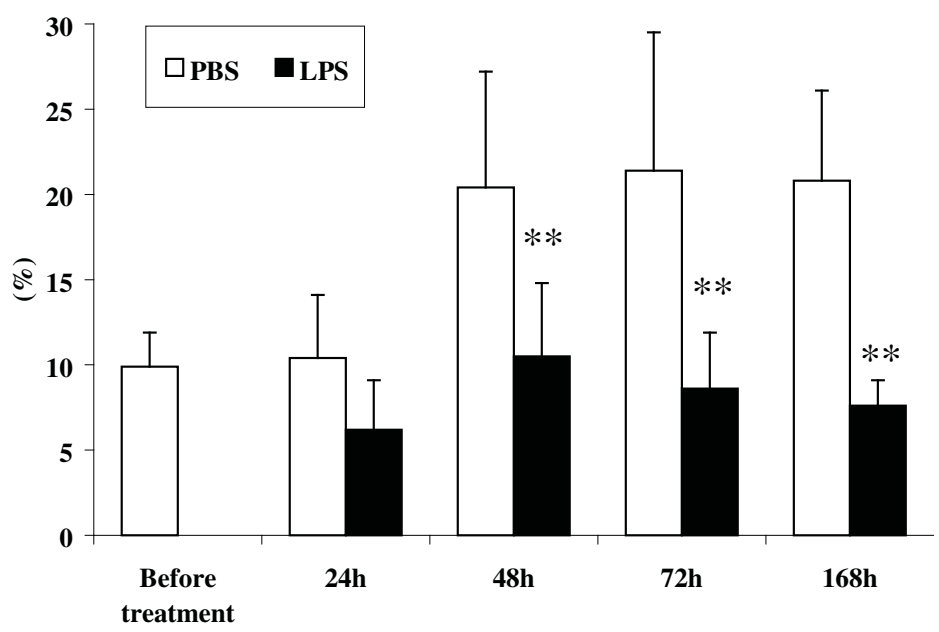

(b)

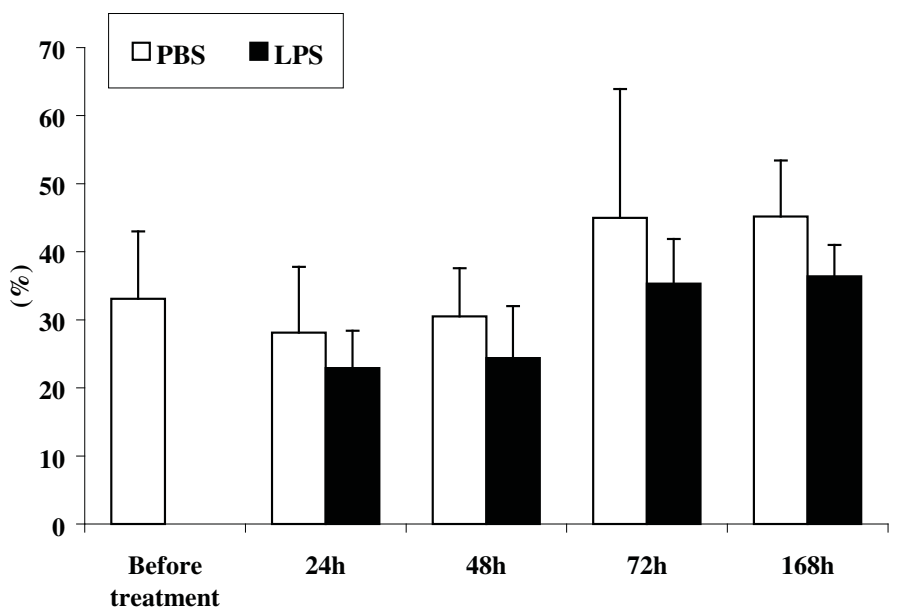

Figure 4 Proportion of apoptotic macrophages in situ. Relative proportion of apoptotic cells in population of non-vacuolized (a) and vacuolized macrophages (b) (mean \pm S.D.) in mammary lavages collected before and $24,48,72$, and $168 \mathrm{~h}$ after intramammary instillation of PBS or LPS. Significant between-treatment differences are marked with asterisks $\left({ }^{* *} P<0.01\right)$.

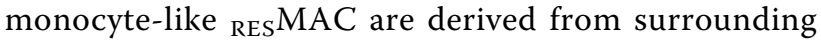
tissues or blood monocytes [3,32]. Migration of these cells can be a constitutive process that occurs at a much lower level in the absence of any apparent cue [33]. After migration into tissues, these monocyte-like cells undergo further differentiation to become multifunctional tissue macrophages with fully developed scavenger function. Apoptotic cell death is, however, required in order for maintain homeostasis [34], and the detection of apoptosis in these cells suggests that monocyte-like RESMAC are not resistant to apoptosis. Moreover, when we cultured these cells in vitro, the proportion of apoptotic cells was significantly increased. This seems to be normal, as it has been shown that monocytes and/or macrophages cultured in vitro without any stimulus become apoptotic within less than $24 \mathrm{~h}$ [35].

The relatively low number of apoptotic monocyte-like RESMAC suggests that the major parts of these cells survive, monitoring inflammatory or other danger signals, and phagocytosing the cellular material of sloughed epithelial and other cells from ducts of mammary glands, as we found in our previous study [17]. As a consequence of their scavenger function, monocyte-like RESMAC may change into vacuolized forms approximately 5 and more days after migration [3]. In the population of vacuolized RESMAC in this study, 
(a)

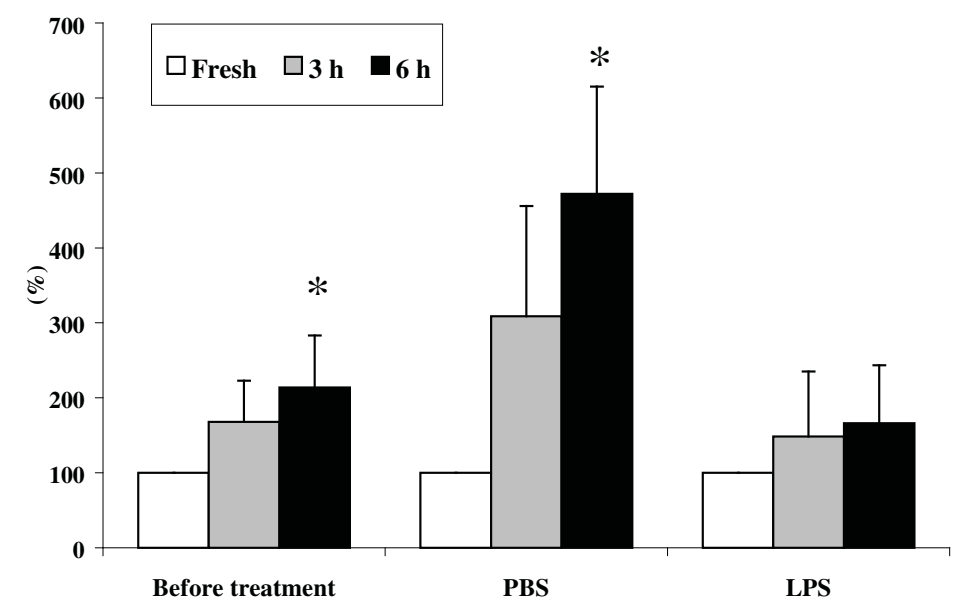

(b)

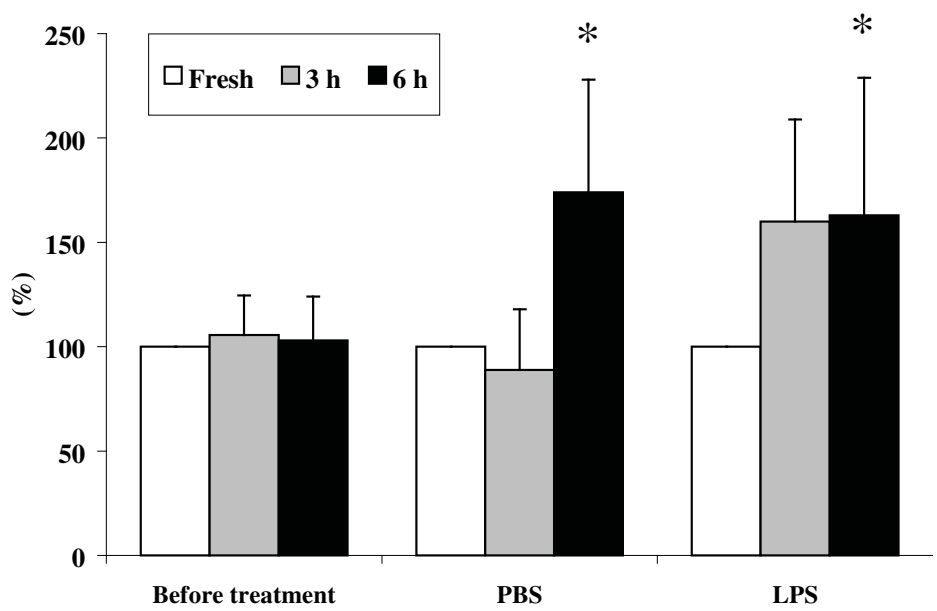

Figure 5 Proportion of apoptotic macrophages in vitro. Relative proportion of apoptotic cells in population of non-vacuolized (a) and vacuolized macrophages (b) obtained before and $24 \mathrm{~h}$ after intramammary instillation of PBS or LPS during in vitro cultivation (mean \pm S.D.). Significant between-treatment differences are marked with asterisks $(* P<0.05)$.

however, we observed a higher proportion of apoptotic cells (33.1\%). A very similar situation seems to be observed in the human lung. In the alveolar microenvironment of the healthy human lung, alveolar macrophages have been shown to have a high apoptotic rate (62.1\%), since apoptotic cell death is required for homeostasis and lung architecture to be maintained [34]. In contrast to monocyte-like RESMAC, the proportion of apoptotic cells was not surprisingly increased after in vitro culturing. This suggests that part of apoptotic vacuolized ${ }_{R E S} M A C$ may consequently undergo secondary necrosis [36] and therefore the proportion of necrotic cells was significantly increased together with LDH concentration during in vitro cultivation, as we have observed recently for a PMN population [28]. Cytolysis of these cells has biological significance in the fact that they released chemotactic factors initiating influx of inflammatory cells.

The intramammary instillation of PBS or LPS resulted in an inflammatory response with a massive influx of PMN during the initial stage. In addition, macrophages also migrated from the blood as monocytes through the surrounding tissues into the mammary gland [25,37]. In contrast to ${ }_{\mathrm{RES}} \mathrm{MAC}$, therefore, these freshly migrated cells expressed high levels of CD11b adhesion receptor [38]. Moreover, the inflammatory forms of macrophages 


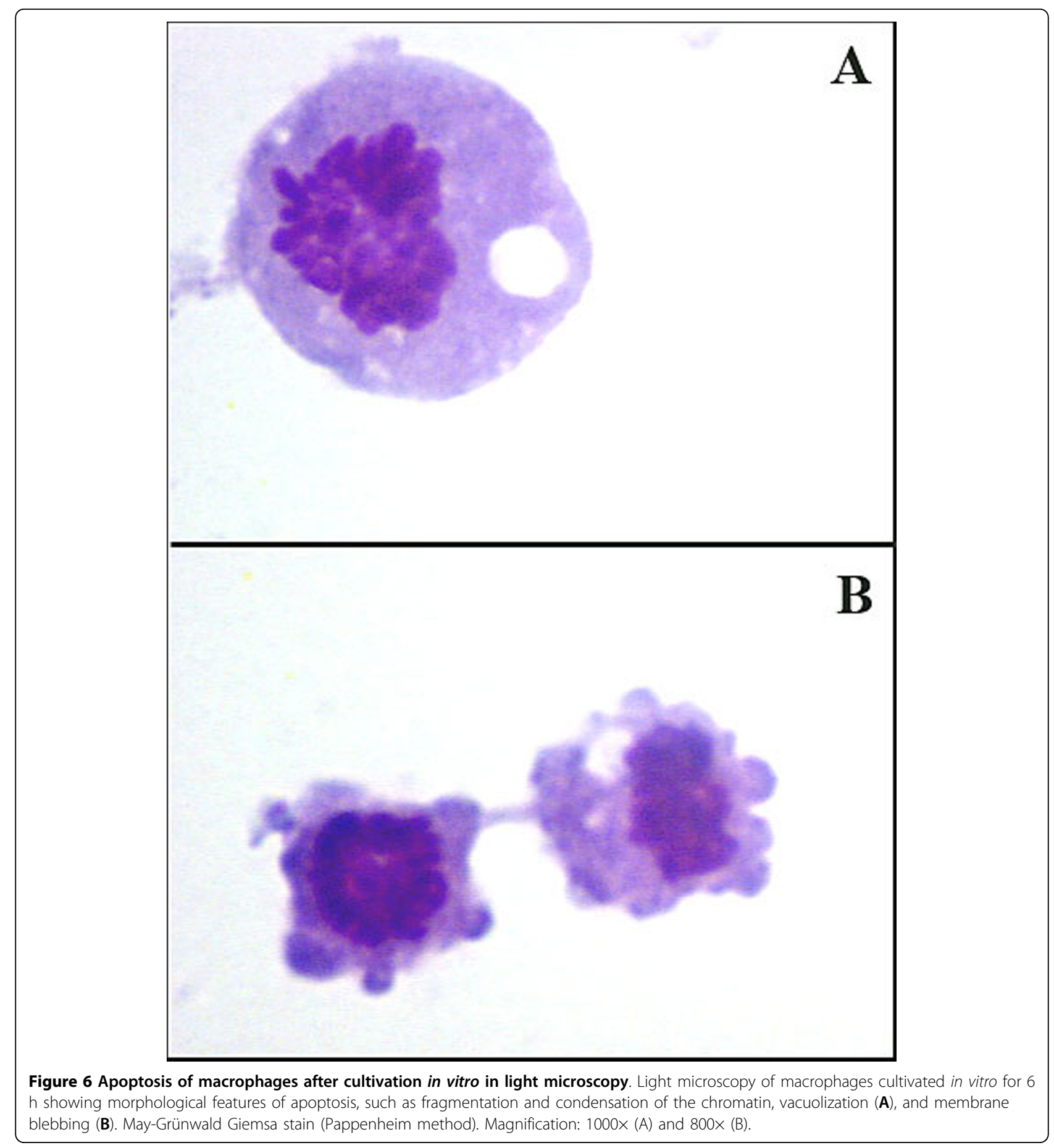

possess monocyte-like morphology and represent a dominant type of macrophages during the initial phase of the inflammatory response [22]. During resolution, however, these cells are vacuolized due to their scavenger function and became numerous during this time. As PMN underwent apoptosis and were subsequently phagocytosed by INFMAC during resolution of the inflammatory response $[9,10]$, it is evident that, similarly to
RESMAC, two morphologically different cells also exist in the ${ }_{\text {INF }}$ MAC population: monocyte-like cells and vacuolized cells. In comparison to vacuolized ${ }_{\text {RES MAC, }}$ however, the vacuolized ${ }_{\text {INF }}$ MAC contain phagocytosed apoptotic PMN in their cytoplasm, as was described in our previous studies $[9,30,39]$.

In this study, we observed approximately $10 \%$ apoptotic and less than 3\% necrotic cells in the fresh 


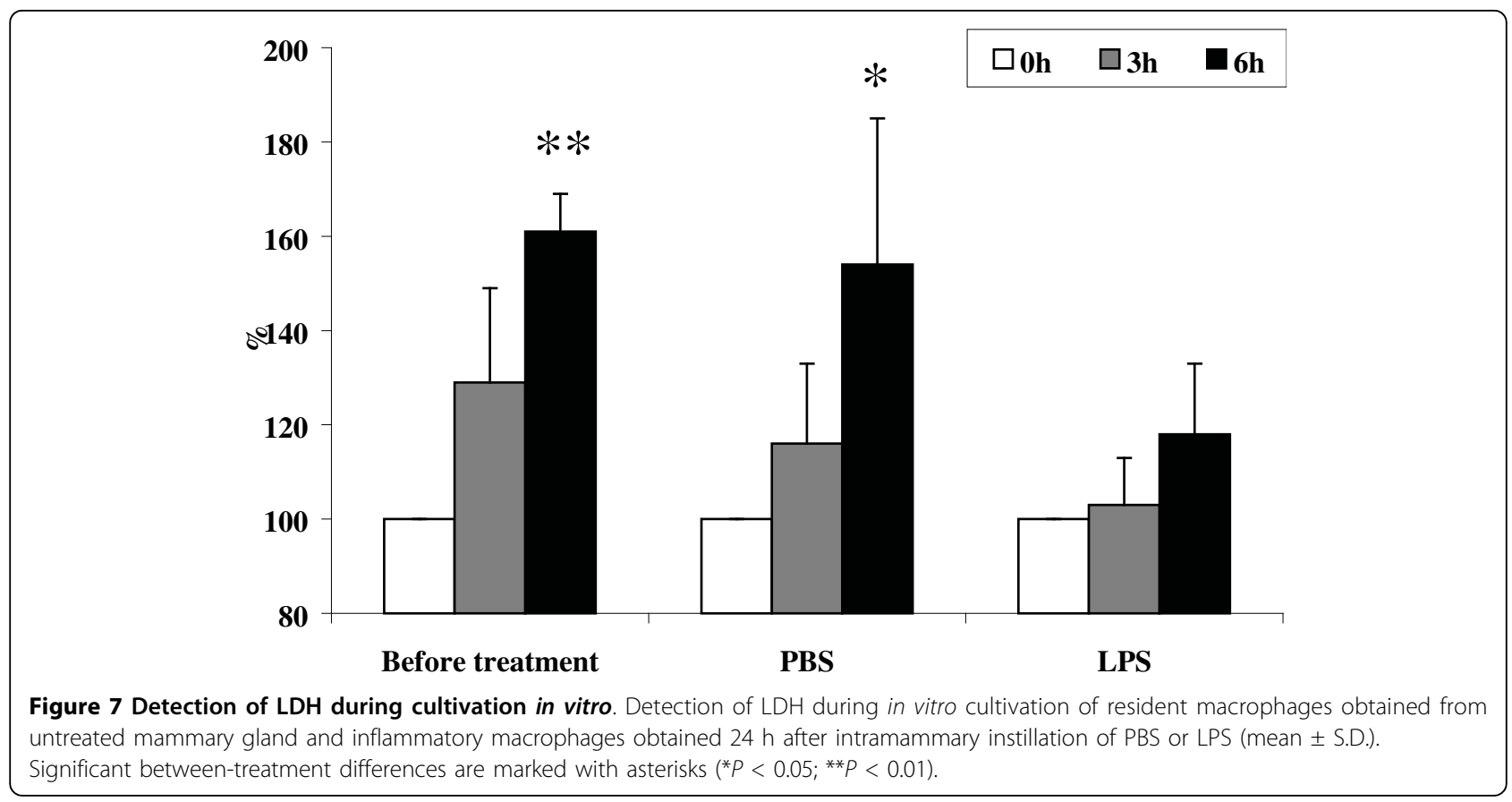

population of monocyte-like ${ }_{\text {INF }}$ MAC $24 \mathrm{~h}$ after PBS treatment and only $5 \%$ apoptotic cells after LPS treatment. Similarly to the situation of monocyte-like RESMAC, this low proportion of death cells is to be expected, because monocyte-like ${ }_{\mathrm{INF}} \mathrm{MAC}$ are relatively young cells derived from monocytes and are rescued from early apoptotic death [40]. Furthermore, we observed differences between treatments in the proportions of apoptotic monocyte-like ${ }_{\text {INF }}$ MAC during the entire experimental period. We assume that after LPS treatment the macrophage apoptosis is halted by inflammatory stimuli that prolong their survival. Since LPS is the most potent factor that rescues monocytes from apoptosis by inducing autocrine synthesis of the inflammatory cytokines, tumor necrosis factor alpha (TNF- $\alpha$ ) and interleukin-1 (IL-1) [41], these cytokines in particular have been detected at increased levels during the initial stage of inflammation caused by Escherichia coli [42]. When we cultured monocyte-like ${ }_{\mathrm{INF}} \mathrm{MAC}$ in vitro, the proportion of apoptotic cells was significantly increased only after PBS, in contrast to LPS. Furthermore, a significant increase in expression of CD14 surface receptor on these cells was recorded after LPS during in vitro cultivation. CD14 is a very important macrophage/monocyte surface molecule shown to induce activation in response to LPS. The aforementioned TNF- $\alpha$ and IL-1 also increase CD14 expression and enhance monocyte survival [43,44]. It is suggested, therefore, that LPS may play an important role in regulating apoptosis not only in PMN [10] but also in macrophages from bovine mammary glands.
Nevertheless, the proportion of apoptotic monocytelike INFMAC was increased by more than twice during resolution of the inflammatory responses caused by PBS and LPS. The literature now contains good evidence that ${ }_{\mathrm{INF}} \mathrm{MAC}$ can undergo apoptosis at the inflamed site even in cases of sterile inflammation. Inflammation caused by noninfective challengers may lead to inducible nitric oxide synthase synthesis and hence high levels of nitric oxide. Nitric oxide is well known as a trigger for macrophage apoptosis [45]. Serum deprivation can also lead to apoptosis in macrophages, albeit at a much lower level than in other cells [46]. It seems that induction of apoptosis in INFMAC is a physiological and altruistic mechanism that may help to reduce inflammatory stress and to avoid the establishment of chronic persistent inflammatory response. In contrast, however, apoptosis of macrophages has also been observed in pathological processes. Recently, it was revealed that induction of macrophage apoptosis and subsequent secondary necrosis is caused by bacterial exotoxin with histotoxic effect [47]. The proapoptotic effect of Mycobacterium tuberculosis on lung macrophages and the contradictory pathogenic effect are also known [48].

Furthermore, we observed that apoptosis in vacuolized ${ }_{\text {INF }} \mathrm{MAC}$ was higher than in monocyte-like ${ }_{\mathrm{INF}} \mathrm{MAC}$ during the entire experimental period and without significant differences between treatments. Surprisingly, we observed no effect of LPS treatment on delay of apoptosis in vacuolized INFMAC during in vitro cultivation. It is known that phagocytosis of apoptotic PMN is associated with apoptosis of macrophages. Local apoptosis 
(a)

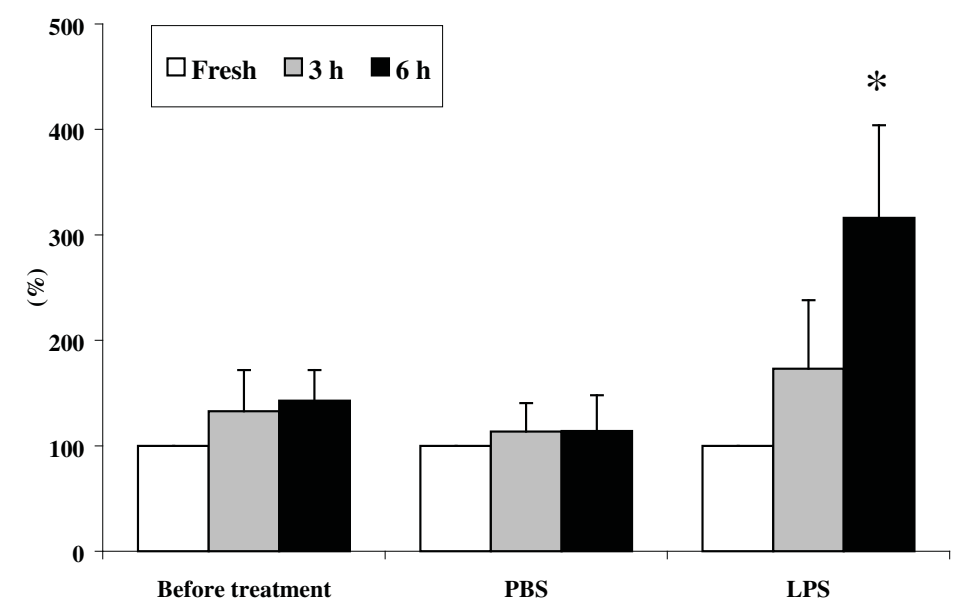

(b)

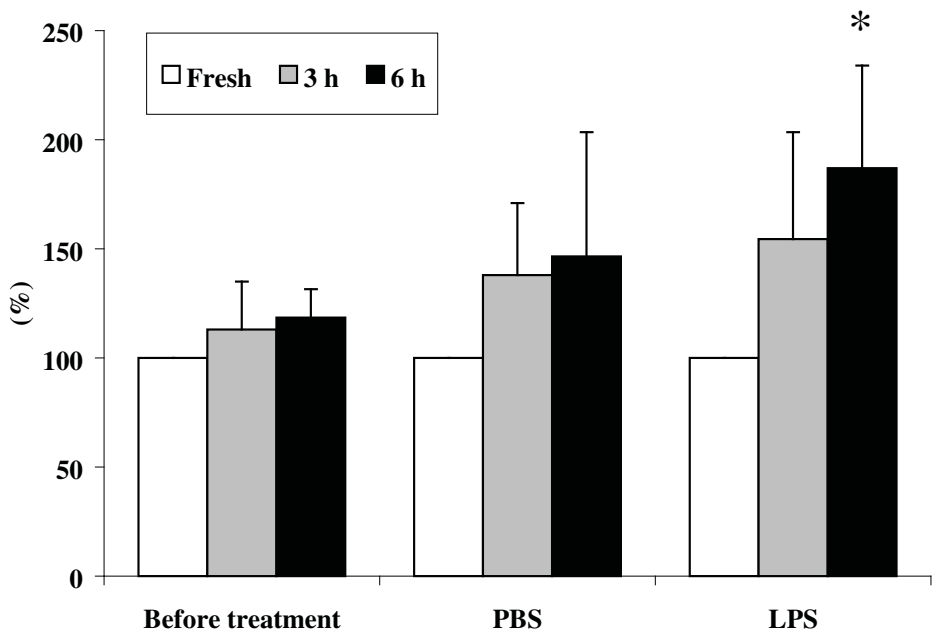

Figure 8 Expression of CD14 in macrophages. Relative proportion of CD14 positive cells in population of non-vacuolized macrophages (a) and vacuolized macrophages (b) obtained before and $24 \mathrm{~h}$ after intramammary instillation of PBS or LPS (mean \pm S.D.). Significant betweentreatment differences are marked with asterisks $(* P<0.05)$.

of macrophages once having ingested apoptotic cells has been observed during inflammation [40]. In this case, the clearance of these macrophages also seems to be an important manner for successfully resolving inflammation.

\section{Conclusion}

In conclusion, our experiments confirmed that macrophages of the heifer mammary glands also undergo apoptosis. We conclude that apoptosis of RESMAC is accompanied by natural senescence. On the other hand, apoptosis of ${ }_{\mathrm{INF}} \mathrm{MAC}$ seems to be one of the important events in resolution of the inflammatory response. In addition, secondary necrosis of apoptotic macrophages and cytolysis was determined. However, the exact role of apoptosis in macrophages from bovine mammary glands, and particularly in host-pathogen interactions, needs to be elucidated in future studies.

\section{Acknowledgements}

This study was supported by the Ministry of Agriculture of the Czech Republic (MZE0002716202). The authors wish to thank Dr. Vladimir Babak for consulting about statistical data procedures. 


\section{Author details}

${ }^{1}$ Department of Morphology, Physiology and Animal Genetics, Mendel University, Zemedelska 1, 61300 Brno, Czech Republic. ${ }^{2}$ Veterinary Research Institute, Hudcova 70, 62132 Brno, Czech Republic.

\section{Authors' contributions}

ZS carried out the practical work, performed flow cytometry analysis, compiled the results, participated in interpretation of results, drafted the manuscript and participated in its revision. DR was mainly responsible for performing the statistical analyses, helped in interpreting the results and revising the manuscript. Both authors read and approved the final manuscript.

\section{Competing interests}

The authors declare that they have no competing interests.

Received: 27 May 2009

Accepted: 9 February 2010 Published: 9 February 2010

\section{References}

1. Fox LK: Prevalence, incidence and risk factors of heifer mastitis. Vet Microbiol 2009, 134:82-88.

2. Pyörälä S: Mastitis in post-partum dairy cows. Reprod Domest Anim 2008, 2:252-259

3. Wardley RC, Rouse BT, Babiuk LA: The mammary gland of the ox: a convenient source for the repeated collection of neutrophils and macrophages. J Reticuloendothel Soc 1976, 19:29-36.

4. Trinidad P: Mastitis in unbred and primigravid dairy heifers. PhD Dissertation Louisiana State University, Baton Rouge, Louisiana 1989.

5. Rysanek D, Sediva A, Sladek Z, Babak V: Intramammary infections of juvenile mammary glands of heifers - Absolute and differential somatic cells counts. Vet Med Czech 1999, 44:199-203.

6. Paape MJ, Mehrzad J, Zhao X, Dettileux J, Burvenich CH: Defense of the bovine mammary gland by polymorphonuclear neutrophil leukocytes. J Mammary Gland Biology and Neoplasm 2002, 7:109-121.

7. Bruckmaier RM: Gene expression of factors related to the immune reaction in response to intramammary Escherichia coli lipopolysaccharide challenge. J Dairy Res 2005, 72:120-124.

8. Targowski SP: Role of Immune Factors in Protection of Mammary Gland J Dairy Sci 1983, 66:1781-1789.

9. Sladek Z, Rysanek D: Apoptosis of polymorphonuclear leukocytes of the juvenile bovine mammary glands during induced influx. Vet Res 2000, 31:553-563.

10. Sladek Z, Rysanek D: Neutrophil apoptosis during resolution of bovine mammary gland injury. Res Vet Sci 2001, 70:41-46.

11. Van Oostveldt $\mathrm{K}$, Vangroenweghe F, Dosogne $\mathrm{H}$, Burvenich C: Apoptosis and necrosis of blood and milk polymorphonuclear leukocytes in early and midlactating healthy cows. Vet Res 2001, 32:617-622.

12. Fujiwara N, Kobayashi K: Macrophages in Inflammation. Curr Drug Tar Inflam Allergy 2005, 4:281-286.

13. Quiroga GH, Sordillo LM, Adkinson RW, Nickerson SC: Cytologic responses of Staphylococcus aureus-infected mammary glands of heifers to interferon gamma and interleukin-2 treatment. Am J Vet Res 1993, 54:1894-1900.

14. Desiderio JV, Campbell SG: Bovine mammary gland macrophages: isolation, morphologic features, and cytophilic immunoglobulins. Am J Vet Res 1980, 41:1595-1599.

15. Bellingan GJ, Caldwell H, Howie SEM, Dransfield I, Haslett CH: In vivo fate of the inflammatory macrophage during the resolution of inflammation. Inflammatory macrophages do not die locally, but emigrate to the draining lymph nodes. J Immunol 1996, 157:2577-2585.

16. Lee CS, Wooding FB, Kemp P: Identification, properties, and differential counts of cell populations using electron microscopy of dry cows secretions, colostrum and milk from normal cows. J Dairy Res 1980, 47:39-50.

17. Sladek Z, Rysanek D: Ultrastructure of phagocytes from mammary glands of non-pregnant heifers. Anat Histol Embryol 1999, 28:291-297.

18. Gonzalez-Mejia ME, Doseff Al: Regulation of monocytes and macrophages cell fate. Front Biosci 2009, 14:2413-2431.

19. Denis M, Wedlock DN, Buddle BM: IFN-gamma enhances bovine macrophage responsiveness to Mycobacterium bovis: Impact on bacterial replication, cytokine release and macrophage apoptosis. Immunol Cell Biol 2005, 83:643-650.

20. Thumbikat P, Dileepan T, Kannan MS, Maheswaran SK: Mechanisms underlying Mannheimia haemolytica leukotoxin-induced oncosis and apoptosis of bovine alveolar macrophages. Microb Pathogen 2005, 38:161-172.

21. Vega-Manriquez X, López-Vidal Y, Moran J, Adams LG, Gutiérrez-Pabello JA Apoptosis-inducing factor participation in bovine macrophage Mycobacterium bovis-induced caspase-independent cell death. Infect Immunol 2007, 75:1223-1228.

22. Sladek Z, Ryznarova H, Rysanek D: Macrophages of the bovine heifer mammary gland: morphological features during initiation and resolution of the inflammatory response. Anat Histol Embryol 2006, 35:116-124.

23. Slama P, Sladek Z, Rysanek D, Langrova T: Effect of Staphylococcus aureus and Streptococcus uberis on apoptosis of bovine mammary gland lymphocytes. Res Vet Sci 2009, 87:233-238.

24. Rysanek D, Babak V, Sladek Z, Toman M: Variation among unbred heifers in the activities of their mammary gland and blood polymorphonuclear leucocytes. J Vet Med B 2001, 18:31-42.

25. Sladek Z, Rysanek D, Faldyna M: Activation of phagocytes during initiation and resolution of mammary gland injury induced by lipopolysaccharide. Vet Res 2002, 33:191-204.

26. European Standard (EN ISO 13366-2), 2006: Mil - Enumeration of somatic cell - Part 2: Guidance on the operation of fluoro-opto-electronic counters.

27. Vermes I, Haanen C, Stefferns-Naaken H, Reutelingsperger CP: A novel assay for apoptosis: flow cytometry detection of phosphatidylserine expression on early apoptotic cells using fluorescein labelled Annexin V. J Immunol 1995, 184:39-51.

28. Rysanek D, Sladek Z, Babak V, Vasickova D, Hubackova M: Spontaneous and induced cytolysis of leukocytes from bovine mammary gland in course of cultivation in vitro - the correlation with neutrophil granulocytes apoptosis. Vet Med Czech 2006, 51:265-277.

29. Matouskova O, Chalupa J, Cigler M, Hruska K: STAT Plus, software manual 1.01. Veterinary Research Institute Brno 1992, 1-168.

30. Sladek Z, Rysanek D, Ryznarova H, Faldyna M: Neutrophil apoptosis during experimentally induced Staphylococcus aureus mastitis. Vet Res 2005, 36:629-643.

31. Sladek Z, Rysanek D: The role of CD14 during resolution of experimentally induced Staphylococcus aureus and Streptococcus uberis mastitis. Comp Immunol Microbiol Infect Dis 2006, 29:243-262.

32. Leitner G, Eligulashvily R, Krifucks O, Perl S, Saran A: Immune cell differentiation in mammary gland tissues and milk of cows chronically infected with Staphylococcus aureus. J Vet Med B 2003, 50:45-52.

33. Zhang X, Mosser DM: Macrophage activation by endogenous danger signals. J Pathol 2008, 214:161-178.

34. Liacos C, Konstadoulakis MM, Economou V, Katsaragakis S, Chatzigianni E, Georgiadis GG, Prekates A, Karampinis A, Bramis J: Increased apoptosis in the alveolar microenvironment of the healthy human lung. J Surg Res 2008, 145:186-191.

35. Kiener PA, Davis PM, Starling GC, Mehlin C, Klebanoff SJ, Ledbetter JA Liles WC: Differential induction of apoptosis by Fas-Fas ligand interactions in human monocytes and macrophages. J Exp Med 1997, 185:1511-1516.

36. Silva MT, do Vale A, dos Santos NM: Secondary necrosis in multicellular animals: an outcome of apoptosis with pathogenic implications. Apoptosis 2008, 13:463-482.

37. Hageltorn M, Saad MA: Flow cytofluorometric characterization of bovine blood and milk leukocytes. Am J Vet Res 1986, 47:2012-2016.

38. Strauss-Ayali D, Conrad SM, Mosser DM: Monocyte subpopulations and their differentiation patterns during infection. J Leukoc Biol 2007, 82:244-252.

39. Rysanek $D$, Sladek $Z$ : The image of exocytosis during neutrophils and macrophages phagocytic activities in inflammation of mammary gland triggered by experimental Staphylococcus aureus infection. Anat Histol Embryol 2006, 35:171-177.

40. Bellingan GJ, Laurent GJ: Fate of macrophages once having ingested apoptotic cells: Lymphatic clearance or in situ apoptosis?. The Resolution of Inflammation Basel: Birkhäuser VerlagRossi AG, Sawatzky DA 2008. 
41. Mangan DF, Welch GR, Wahl SM: Lipopolysaccharide, tumor necrosis factor-alpha, and IL-1 beta prevent programmed cell death (apoptosis) in human peripheral blood monocytes. J Immunol 1991, 146:1541-1546.

42. Bannerman DD, Paape MJ, Lee JW, Zhao X, Hope JC, Rainard P: Escherichia coli and Staphylococcus aureus elicit differential innate immune responses following intramammary infection. Clin Diagn Lab Immunol 2004, 11:463-472.

43. Ziegler-Heitbrock HW, Ulevitch RJ: CD14: cell surface receptor and differentiation marker. Immunol Today 1993, 14:121-125.

44. Malyshev IY, Shnyra A: Controlled modulation of inflammatory, stress and apoptotic responses in macrophages. Curr Drug Targets Immune Endocr Metabol Disord 2003, 3:1-22.

45. Albina JE, Reichner JS: Role of nitric oxide in mediation of macrophages cytotoxicity and apoptosis. Canc Met Rev 1998, 17:39-53.

46. Wei J, Sun Z, Chen Q, Gu J: Serum deprivation induced apoptosis in macrophage is mediated by autocrine secretion of type I IFNs. Apoptosis 2006, 11:545-554.

47. do Vale A, Costa-Ramos C, Silva A, Silva DS, Gärtner F, dos Santos NM, Silva MT: Systemic macrophage and neutrophil destruction by secondary necrosis induced by a bacterial exotoxin in a Gram-negative septicaemia. Cell Microbiol 2007, 9:988-1003.

48. Lee J, Hartman M, Kornfeld H: Macrophage apoptosis in tuberculosis. Yonsei Med J 2009, 50:1-11.

doi:10.1186/1751-0147-52-12

Cite this article as: Sladek and Rysanek: Apoptosis of resident and inflammatory macrophages before and during the inflammatory response of the virgin bovine mammary gland. Acta Veterinaria Scandinavica 2010 52:12.

\section{Submit your next manuscript to BioMed Central and take full advantage of:}

- Convenient online submission

- Thorough peer review

- No space constraints or color figure charges

- Immediate publication on acceptance

- Inclusion in PubMed, CAS, Scopus and Google Scholar

- Research which is freely available for redistribution

Submit your manuscript at www.biomedcentral.com/submit
Biomed Central 